\title{
A computational approach for modeling the infant vision system in object and face recognition Roberto A Vazquez* and Humberto Sossa
}

\author{
Address: Center for Computing Research, National Polytechnic Institute, Mexico City, Mexico, 07738. \\ Email: Roberto A Vazquez* - ravem@ipn.mx \\ * Corresponding author
}

from Sixteenth Annual Computational Neuroscience Meeting: CNS*2007

Toronto, Canada. 7-12 July 2007

Published: 6 July 2007

BMC Neuroscience 2007, 8(Suppl 2):P204 doi:I0.I I86/I47|-2202-8-S2-P204

@ 2007 Vazquez and Sossa; licensee BioMed Central Ltd.

\section{Background}

Most research in vision systems has been focused on the fully developed visual system of adult humans. During early developmental stages, there are communication pathways between the visual and other sensory areas of the cortex, showing how the biological network is selforganizing. Within a few months of birth, the brain can differentiate faces from other faces or objects from other objects.

\section{Proposal}

In this research, we investigate the learning process of face and object recognition of the infant's brain. The biological hypotheses of this model are based on the role of responses to low frequencies in early stages [1], and some conjectures concerning to how an infant detects subtle features (stimulating points) in a face or object [2]. We simulate the infant's brain using the dynamic associative model (DAM) deeply described in [3]. This model changes their synapse connection strengths according to an input stimulus based on the Hebbian learning rule. The model for infant vision consists of a DAM used to recognize different images of faces and objects. As the infant vision responds to low frequencies of the signal, a low-filter is first used to remove high frequency components from the image. Then we detect subtle features in the image by means of a random selection of stimulating points. At last, the DAM is fed with this information for training and recognition (Fig. 1).

\section{Results}

To test the accuracy of the model, we performed two experiments. In experiment 1 , we used a benchmark of faces of 15 different people (Fig. 2). In experiment 2, we use a benchmark of 5 objects (Fig. 3). During the training process in both experiments, the DAM performed with $100 \%$ accuracy using only one image of each person and object. During testing, the DAM performed in average with 99\% accuracy for the remaining 285 images of faces (experiment 1) and $99 \%$ accuracy for the remaining 90 images of objects (experiment 2) by using different sizedfilter and stimulating points.

\section{Conclusion}

The model learned to distinguish faces and objects accurately in a similar manner that an infant's brain builds the neural connections after birth. Preprocessing images used to remove high frequencies and random selection of stim-

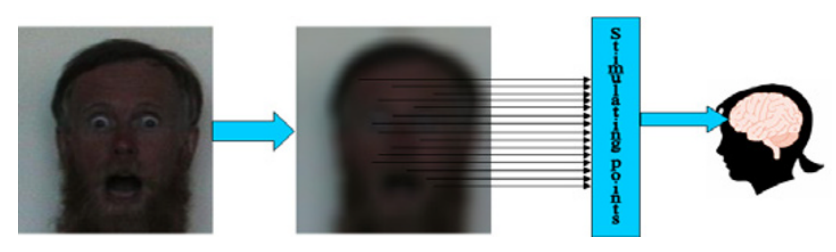

Figure I

Schematic representation of the model. 


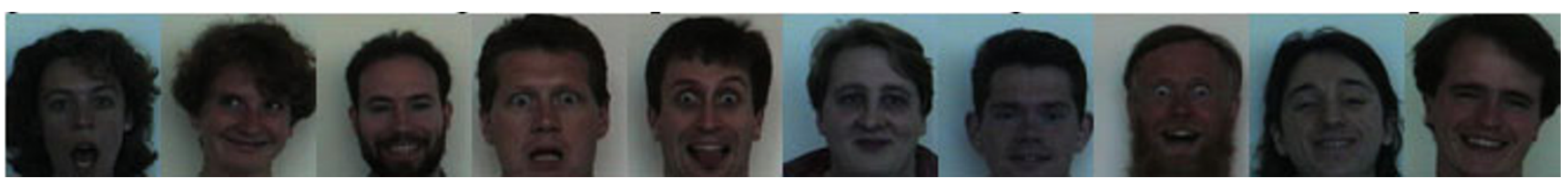

\section{Figure 2}

Some of the 20 images of each person with different gesticulations used in experiment I.
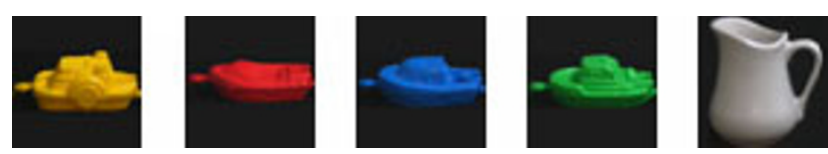

\section{Figure 3}

Some of the 20 images of each object at different orientations (from 0 to 95 degrees) used in experiment 2.

ulating points contribute to eliminating unnecessary information and help the DAM to learn efficiently the faces and the objects. Successful results suggest the proposal could serve as a biological model to explain the learning process in infant's brain for face and object recognition.

\section{Acknowledgements}

This work was economically supported by SIP-IPN under grants 2007I 438 and CONACYT under grant 46805.

\section{References}

I. Banks MS, Salapatek P: Infant pattern vision: a new approach based on the contrast sensitivity function. J Exp Child Psychol $3 I(1): I-45$.

2. Tondel GM, et al.: Infants' ability to track ramp accommodative stimuli. ARVO 2002.

3. Vazquez RA, Sossa H: A new associative memory with dynamical synapses. Submitted to IJCNN 2007.

Publish with Bio Med Central and every scientist can read your work free of charge

"BioMed Central will be the most significant development for disseminating the results of biomedical research in our lifetime. "

Sir Paul Nurse, Cancer Research UK

Your research papers will be:

- available free of charge to the entire biomedical community

- peer reviewed and published immediately upon acceptance

- cited in PubMed and archived on PubMed Central

- yours - you keep the copyright
BioMedcentral 